\title{
PALHA DE CANA-DE-AÇÚCAR COMO MATÉRIA-PRIMA NA OBTENÇÃO DE FIBRAS CELULÓSICAS PARA PAPEL $\left({ }^{1}\right)$
}

\author{
ANISIO AZZINI $\left(^{2,4}\right)$, LEO ZIMBACK $\left({ }^{3}\right)$ \\ e ROSE MARRY ARAÚJO GONDIM-TOMAZ $\left({ }^{2}\right)$
}

\begin{abstract}
RESUMO
No presente estudo, procedeu-se à caracterização morfológica das fibras celulósicas obtidas a partir da palha de cana-de-açúcar. Esse material, classificado como um resíduo fibroso, apresentou comprimento médio $(1,24 \mathrm{~mm})$ intercalado das fibras do eucalipto $(1,0 \mathrm{~mm})$ e do Pinus $(4,0 \mathrm{~mm})$, principais fontes de matérias-primas celulósicas. Para as demais dimensões da fibra, os valores médios obtidos foram de 4,33, 4,15 e 12,80 $\mu \mathrm{m}$, respectivamente, para a espessura da parede celular, diâmetro do lume e largura da fibra. Embora os rendimentos em fibras, tanto no processo ácido $(34,63 \%)$ como no básico $(33,97 \%)$, tenham sido relativamente baixos, esse material, pelas características micrométricas das fibras, pode ser utilizado na obtenção de celulose e papel, para usos que requeiram baixos níveis de resistência.
\end{abstract}

Termos de indexação: palha de cana-de-açúcar, resíduo agrícola, fibras celulósicas.

\section{ABSTRACT \\ SUGARCANE STRAW AS RAW MATERIAL TO PRODUCE CELLULOSIC FIBERS FOR PAPERMAKING}

The morphological characteristics of cellulosic fibers obtained from sugarcane straw were determined. This material, a fibrous residue, presented fiber length ( 1.24 $\mathrm{mm})$ between the eucaliptus $(1.0 \mathrm{~mm})$ and Pinus $(4.0 \mathrm{~mm})$ fiber lengths, whose woods are the main cellulosic raw material used to produce pulp and paper. The average values for wall thickness, lumen diameter and fiber width were, respectively $4.33,4.15$ and $12.80 \mu \mathrm{m}$. Although, the fiber yields obtained in acid (34.63\%) or alkaline $(33.97 \%)$ conditions were low in comparison with that obtained for wood species, the sugarcane straw is adequate to be used as raw material for papermaking.

Index terms: sugarcane straw, agricultural residue, cellulosic fiber.

( $\left.{ }^{1}\right)$ Trabalho recebido para publicação em $1 .^{\circ}$ de junho de 1965 e aceito em 31 de janeiro de 1996.

(2) Seção de Tccnologia de Fibras, Instituto Agronômico (IAC), Caixa Postal 28, 13001-970 Campinas (SP).

(3) Estação Experimental de Piracicaba, IAC.

$\left({ }^{4}\right)$ Com bolsa de pesquisa do CNPq. 
A palha de cana-de-açúcar, representada basicamente por folhas secas de cana, é um resíduo fibroso encontrado nos canaviais em quantidade apreciável. Normalmente, esse material é destruído durante a queima dos canaviais, apesar da existência de um Decreto Estadual proibindo esse procedimento. A queima, além de destruir um subproduto que pode ter uma utilizaçâo econômica, provoca elevação dos níveis de poluição atmosférica. Segundo Ripoli (1991), as concentrações de ozônio e monóxido de carbono, nas épocas de queimada, elevam-se na baixa atmosfera, prejudicando o desenvolvimento dos vegetais e o sistema respiratório dos animais. Em condições normais, as concentrações de ozônio e monóxido de carbono são, respectivamente, 30 e $100 \mathrm{ppb}$. Nas mesmas regiões, em épocas de queimadas de cana, essas concentrações se elevam para 80 e 600 ppb.

O objetivo deste estudo foi promover uma caracterização morfológica das fibras celulósicas obtidas a partir da palha de cana-de-açúcar e oferecer subsídios para o seu uso na obtenção de celulose e papel.

\section{Material e Métodos}

A palha-de-cana do presente estudo foi fornecida pela Estação Experimental de Piracicaba, do Instituto Agronômico. No laboratório, esse material, constituído por folhas secas de cana que se apresentavam inteiras ou subdivididas, foi amostrado para as determinações dos teores de matéria seca e rendimentos de conversão em fibras celulósicas. Tais rendimentos foram obtidos após o tratamento ácido e o alcalino. No alcalino, empregou-se a solução de hidróxido de sódio a $5 \%$, mantida por duas horas em banho-maria à temperatura de $70^{\circ} \mathrm{C}$. O ácido desenvolveu-se em solução altamente oxidante, composta de ácido acético glacial (50\%), água oxigenada a $29,3 \%(40 \%)$ e água destilada (10\%). Esse tratamento, à semelhança do anterior, foi mantido em banho-maria a $70^{\circ} \mathrm{C}$ até completa deslignificação das amostras.

Realizou-se o estudo micrométrico das fibras celulósicas em quatro regiões da folha (bainha, base, meio e ponta), amostrando-se, para tanto, 50 folhas inteiras selecionadas no material recebido.
A seguir, determinaram-se as massas dessas regiões. A maceração das amostras, considerando as quatro regiões da folha, foi conseguida conforme preconizado por Azzini et al. (1993).

O comprimento, a espessura e o diâmetro do lume foram obtidos com o auxílio de microscópio provido de ocular micrométrica com filamento móvel. Para cada região da folha, foram dimensionadas 120 fibras, num total de 480. A largura da fibra foi calculada indiretamente, somando-se duas vezes o valor da parede celular e o diâmetro do lume.

Além das dimensões fundamentais da fibra, calcularam-se as principais relações entre essas dimensões, para melhor avaliar as propriedades físico-mecânicas do papel produzido a partir dessas fibras. Essas relações foram obtidas conforme procedimento utilizado por Barrichello et al. (1984).

\section{Resultados e Discussão}

O quadro 1 mostra a massa seca da folha de cana-de-açúcar e a das quatro regiões preestabelecidas para este estudo.

Quadro 1. Matéria seca da folha de cana-de-açúcar, considerando quatro regiões( $\left.{ }^{1}\right)$

\begin{tabular}{lcc}
\hline Região & Matéria seca & Desvio-padrão \\
\cline { 2 - 3 } & & \\
Bainha & $3,58 \pm 1,26$ & 0,64 \\
Base & $1,68 \pm 0,64$ & 0,33 \\
Meio & $1,37 \pm 0,59$ & 0,30 \\
Ponta & $1,28 \pm 1,06$ & 0,54 \\
Folha & $7,91 \pm 1,96$ & 1,00 \\
\hline
\end{tabular}

(') Médias de 50 folhas.

Considerando as dimensões e o volume da folha de cana em relação a sua massa média $(7,90 \mathrm{~g})$, pode-se concluir que se trata de um material leve e bastante volumoso, dificultando o manuseio e o transporte. Quanto à massa das regiões conside- 
radas, observa-se que o peso da bainha $(3,58 \mathrm{~g})$ se aproxima da do limbo da folha $(4,23 \mathrm{~g})$, que corresponde à soma das regiões da base $(1,68 \mathrm{~g})$, meio $(1,37 \mathrm{~g})$ e ponta $(1,28 \mathrm{~g})$.

No quadro 2, encontram-se os rendimentos de conversão em fibras celulósicas e matéria seca na palha da cana. Esses dados mostram que os rendimentos obtidos $(33,97 \%$ e $34,63 \%)$ são mais baixos do que aqueles das madeiras ( $50 \%$ ) tradicionalmente utilizadas na produção de celulose e papel. Quanto à matéria seca, o teor observado $(91,57 \%)$ evidencia que se trata de um material praticamente livre de umidade, sem nenhuma atividade fisiológica. Nessas condições, as folhas permaneccm nas áreas de cultivo como um resíduo vegetal.

Quadro 2. Rendimento em fibras celulósicas e matéria seca na palha de cana-de-açúcar

Tratamento $\begin{gathered}\text { Rendimento de } \\ \text { conversão }\left({ }^{1}\right)\end{gathered} \quad$ Matéria seca $\left({ }^{2}\right)$

$\begin{array}{lll}\text { Ácido } & 34,63 \pm 1,10 & \\ \text { Básico } & 33,97 \pm 0,45\end{array} \quad 91,57 \pm 0,18$

(1) Médias de cinco repetiçōes. ( $\left.{ }^{2}\right)$ Médias de três repetições.
As dimensões das fibras celulósicas obtidas em quatro regiōes da folha de cana (Quadro 3) apresentaram variações apenas em relação ao comprimento. A única variação significativa observada ao nível de $5 \%$ foi entre as fibras da bainha $(1,30$ $\mathrm{mm})$ e da base do limbo $(1,10 \mathrm{~mm})$. Para as dimensões transversais da fibra (espessura da parede celular, lume e largura), não houve variações significativas. Os valores médios obtidos para as regiōes consideradas na folha foram de 4,24 a 4,41 $\mu \mathrm{m}$ para a parede celular, de 3,06 a $4,68 \mu \mathrm{m}$ para o diâmetro do lume e de 11,88 a $13,29 \mu \mathrm{m}$ para a largura das fibras.

A principal dimensão da fibra celulósica que caracteriza as matérias-primas fibrosas é o comprimento. No caso da palha de cana, o comprimento médio das fibras celulósicas $(1,24 \mathrm{~mm})$ posiciona-se entre o das fibras do eucalipto $(1,0 \mathrm{~mm})$ e o do Pinus $(4,0 \mathrm{~mm})$ considerados, respectivamente, como fibras curtas e longas. As madeiras de Pinus e eucaliptos são nossas principais matérias-primas na produção de papel, representando mais de $90 \%$ do material fibroso empregado. Em comparação com as fibras do eucalipto, as da palha de cana são ligeiramente mais longas e mais estreitas. As fibras da palha devem conferir ao papel menor resistência ao rasgamento, uma vez que o seu menor

Quadro 3. Dimensões das fibras celulósicas de quatro regiões de folha seca de cana-de-açúcar( ${ }^{1}$ )

\begin{tabular}{lcccc}
\hline Região da folha & Comprimento & Parede celular & Lume & Largura \\
\hline & $\mathrm{mm}$ & & $\mu \mathrm{m}$ & \\
Bainha & $1,39 \mathrm{a}$ & 4,30 & 4,68 & 13,29 \\
Base & $1,10 \mathrm{~b}$ & 4,36 & 4,28 & 12,99 \\
Meio & $1,31 \mathrm{ab}$ & 4,24 & 4,57 & 13,05 \\
Ponta & $1,15 \mathrm{ab}$ & 4,41 & 3,06 & 11,88 \\
\hline Média & 1,24 & 4,33 & 4,15 & 12,80 \\
\hline F & & & & - \\
Tukey a 5\% & $3,05^{*}$ & $0,22 \mathrm{~ns}$ & - & - \\
Desvio-padrão & 0,29 & - & $2,69 \mathrm{~ns}$ & - \\
C.V.(\%) & 0,43 & 19,33 & 59,67 & - \\
\end{tabular}

( $\left.{ }^{1}\right)$ Médias de 30 determinações. 
comprimento deve resultar em menores possibilidades de ligações interfibras.

Quanto às relações entre as dimensões das fibras de palha de cana (Quadro 4), os valores para o coeficiente de enfeltramento, coeficiente de flexibilidade, fração parede e índice de Runkel foram, respectivamente, $74 \%, 32 \%, 214 \%$ e $2,15 \%$. Para as fibras de Eucalyptus urophylla, esses valores, segundo Barrichello et al. (1984), foram: 60\%, 50\%, $50 \%$ e $1,01 \%$.

O índice de enfeltramento, à semelhança do comprimento da fibra, relaciona-se positivamente com

Quadro 4. Relações entre as dimensões das fibras celulósicas obtidas na palha de cana-de-açúcar

Relação

Palha de cana-de-açúcar

Índice de enfeltramento $\left({ }^{1}\right)$ 74

Coeficiente de flexibilidade $\left(^{2}\right)(\%)$ 32

Fração parede $\left(^{3}\right)(\%)$ Índice de Runkel( $\left.{ }^{4}\right)$

( $\left.{ }^{\mathrm{I}}\right) \mathrm{IE}=$ (Comprimento da fibra/largura da fibra $) .\left({ }^{2}\right) \mathrm{CF}=(100$ $\mathrm{x}$ diâmetro do lume $) /$ lume. $\left({ }^{3}\right) \mathrm{FP}=(200 \mathrm{x}$ espessura da parede celular $) /$ largura. $\left({ }^{4}\right) \mathrm{IR}=(2 \times$ espessura da parede celular $) /$ lume. a resistência ao rasgamento do papel. O coeficiente de flexibilidade tem influência direta na resistência à tração e ao arrebentamento do papel. Para essas mesmas propriedades, o índice de Runkel e a fração parede apresentam uma relação inversa.

Pelas suas características morfológicas, as fibras da palha de cana-de-açúcar podem ser utilizadas na produção de celulose para usos que não requeiram altos níveis de resistência físico-mecânica. O aproveitamento desse material como matéria-prima celulósica oferece novas opções econômicas para esse resíduo vegetal, desestimulando sua destruição e, conseqüentemente, a da queima dos canaviais.

\section{REFERÊNCIAS BIBLIOGRÁFICAS}

AZZINI, A.; SALGADO, A.L.B.; BENATTI JUNIOR, R. \& COSTA, A.A. Caracterização tecnológica das espécies liberianas para o estabelecimento de métodos de análise quantitativa de fibras. Bragantia, Campinas, 52(1):27-32, 1993.

BARRICHELLO, L.E.G.; MARIYOSHI, A.H.; BEIG, O. \& DINIZ, A.S. Variação das características da madeira de eucalipto para diferentes espécies, idade e locais. In: CONGRESSO ANUAL DA ASSOCIAÇÃO BRASILEIRA DE CELULOSE E PAPEL, 27., São Paulo, 1984. Anais. São Paulo, ABCP, 1984. v.1., p.385-399.

RIPOLI, T.C.C. Utilização do material remanescente da colheita da cana-de-açucar (Saccharum spp). Equacionamento dos balanços energético e econômico. Piracicaba, 1991. 150p. Tese (Livre-Docência). ESALQ-USP, 1991. 